\title{
Does amblyopia affect educational, health, and social outcomes? Findings from 1958 British birth cohort
}

\author{
J S Rahi, P M Cumberland, C S Peckham
}

\begin{abstract}
Objective To determine any association of amblyopia with diverse educational, health, and social outcomes in order to inform current debate about population screening for this condition.

Design, setting, and participants Comparison of 8432 people with normal vision in each eye with $429(4.8 \%)$ people with amblyopia (childhood unilateral reduced acuity when tested with correction and unaccounted for by eye disease) from the 1958 British birth cohort, with respect to subsequent health and social functioning.

Results No functionally or clinically significant differences existed between people with and without amblyopia in educational outcomes, behavioural difficulties or social maladjustment, participation in social activities, unintended injuries (school, workplace, or road traffic accidents as driver), general or mental health and mortality, paid employment, or occupation based social class trajectories.

Conclusions It may be difficult to distinguish, at population level, between the lives of people with amblyopia and those without, in terms of several important outcomes. A pressing need exists for further concerted research on what it means to have amblyopia and, specifically, how this varies with severity and how it changes with treatment, so that screening programmes can best serve those who have the most to gain from early identification.
\end{abstract}

\section{Introduction}

Amblyopia (literally "blunt sight") is potentially remediable visual loss, usually affecting one eye, arising from an insult (or insults) to the developing visual system in early life. It has long been the subject of basic scientific and clinical research aimed at understanding normal visual development and neural plasticity. ${ }^{12}$ Centuries after the earliest writings, the management of amblyopia continues to challenge clinicians, remaining the most commonly encountered condition in paediatric ophthalmic practice. Whole population screening is now well established in many industrialised countries, aiming to detect affected children so that they can be treated within the "critical period." This practice arose piecemeal-in Britain it emerged in the 1960s from a perceived need by professionals and has been implemented in various ways in the context of child health surveillance. ${ }^{3}$ Recently formulated national guidance in the United Kingdom advocates screening of children aged 4-5 years (most easily achieved at school entry) by orthoptists with expertise in assessing vision and eye movements. ${ }^{4}$ The value of screening has recently been much debated. ${ }^{35}$ This partly reflects concerns about the paucity of evidence of the functional consequences of amblyopia and their impact at a population level, a key factor in assessing the value of screening and its effectiveness. From a national cohort study, we report an investigation of the association of amblyopia with diverse health and social outcomes.

\section{Methods}

The 1958 British birth cohort initially comprised everyone born in Britain in one week in 1958. ${ }^{6}$ Members have been followed since birth, by clinical examination, interview, or both at 7, 11, 16, 23, 33, and 41 years. Data have been collected about many biological, social, and lifestyle factors. Despite some attrition, those cohort members remaining were representative of the original sample, including with respect to vision status.

By using Snellen charts, distance visual acuity in each eye was assessed with habitual correction at 7, 11, and 16 years, together with an examination for strabismus by trained medical examiners. Parents and medical examiners reported eye diseases or operations throughout childhood, including information about occlusion, strabismus surgery, and optical correction. For this analysis, we excluded people with bilateral visual loss, unilateral loss inconsistent with amblyopia, or known eye diseases (such as cataract), as well as those whose vision was tested without their prescribed optical correction. We identified and compared people who, at the age of 16 , were in one of the following mutually exclusive "vision" categories, based on acuity tested with correction if prescribed: normal vision-acuity of $6 / 6$ with or without correction in each eye throughout childhood; mild ("residual/persisting") amblyopia-acuity of $6 / 6$ in one eye and $6 / 9$ or $6 / 12$ in the other and unilateral visual loss, with or without strabismus, earlier in childhood; moderate or severe ("residual/persisting") amblyopia-acuity of $6 / 6$ in one eye and $6 / 18$ or worse in the other and unilateral visual loss, with or without strabismus, earlier in childhood.

For completeness, we analysed separately those with "resolved" amblyopia-that is, with acuity of 6/6 in each eye at 16 years but with unilateral visual loss, with or without strabismus, earlier in childhood, all of whom had had treatment for amblyopia (see tables C and D on bmj.com).

In the absence of information about the functional consequences of amblyopia and their impact at a population level, we elected to investigate key outcomes across the life course in the spheres of education, occupation, and employment; general and mental health; and social interactions and 
behaviours, as a means of capturing any important functional correlates. We assessed the associations of amblyopia with:

- Education-age appropriate tests (described elsewhere ${ }^{7}$ ) of mathematics, reading, comprehension, and perceptual and motor skills at 7, 11, and 16 years, comparing standardised $\mathrm{z}$ scores as a measure of a given child's relative position in the population at each testing age

- Coordination-assessed by a medical examiner (heel to toe standing, finger-nose touching, finger tapping, catching a ball) at 16 years

- Highest educational qualification attained by 33 years (none, less than $\mathrm{O}$ level or equivalent, $\mathrm{O}$ level or equivalent, $\mathrm{A}$ level or equivalent, or higher)

- Behavioural difficulties or social maladjustment at school or at home-by convention the highest decile of scores on the Bristol social adjustment guides and Rutter scales ${ }^{89}$ respectively at 7 and 11 years

- Participation in sport/outdoor games at 11, 16, and 23 years

- Social activities (going dancing or to the cinema, meeting friends) at 16 and 23 years

- Unintended injury needing hospital care, including at school, in the workplace, and road traffic accidents as a driver, between 11 and 33 years

- General health, self reported at 23,33, and 41 years as excellent, good, fair, or poor

- Mental health, comprising self report of seeing a doctor for depression and psychological distress (a score of $\geq 7$ on the malaise inventory ${ }^{9}$ ) at 23,33 , and 41 years

- Employment experience, comprising paid employment histories by 33 years

- Occupation, ${ }^{10}$ comprising working, at age 33 years, in "target" jobs for which minimum visual acuity statutory requirements exist in the UK (table 1) ${ }^{11}$

- Differential impact on occupation based social class potentially related to job preclusion, assessed as change from "expected" social class to "actual" social class (Registrar General's classification) by comparing cohort members' father's occupation at birth and own occupation at 33 years and identifying three broad trajectories of no change, upward change, and downward change

- All cause mortality.

Of the outcomes assessed, educational attainment, employment, and unintended injuries could arguably be considered the main outcomes of interest in relation to the debate on the value of population screening.

\section{Statistical analysis}

After initial descriptive analysis, we investigated amblyopia as a risk factor for adverse outcomes by using linear, logistic, or ordinal logistic regression techniques, as appropriate, and adjusting for factors considered from the extant literature to be potential confounders, including sex, birth weight, social class, and highest educational attainment. The sample eligible for inclusion in the study enabled at least $85 \%$ power to detect an adjusted odds ratio of 1.5 or more for people with mild amblyopia and an adjusted odds ratio of 2.0 or more for those with moderate or severe amblyopia for outcomes with a prevalence of $15 \%$ or more.

To ensure the independent effects of strabismus in itself were accounted for, we also adjusted analyses for ever having had a strabismus. We compared children with strabismus but normal $(6 / 6)$ acuity bilaterally at ages 7,11 , and $16(n=183,37.7 \%$ of all children with strabismus) with those with normal vision without strabismus; the outcomes did not differ, and we retained the first group in the "normal vision" category for analysis.
Table 1 Occupations in United Kingdom with minimum visual acuity requirements ${ }^{11}$

\begin{tabular}{|c|c|}
\hline Vision in worse eye with correction & Job excluded \\
\hline Less than $6 / 60$ & $\begin{array}{l}\text { Merchant Navy (engine room, radio staff, catering } \\
\text { department, surgeon) }\end{array}$ \\
\hline $6 / 60$ & All army regiments \\
\hline $6 / 36$ & All Royal Navy duties \\
\hline \multirow{10}{*}{$6 / 18$} & Large goods vehicle driver \\
\hline & Bus driver \\
\hline & Post Office driver \\
\hline & Metropolitan cab driver \\
\hline & Private pilot \\
\hline & Train driver \\
\hline & London Transport driver \\
\hline & Fork lift truck driver \\
\hline & Police \\
\hline & Prison officer \\
\hline \multirow{7}{*}{$6 / 12$} & Commercial pilot \\
\hline & Flight navigator \\
\hline & Flight engineer \\
\hline & Air traffic control officer \\
\hline & All non-flying Royal Air Force personnel \\
\hline & Merchant seaman (deck duties) \\
\hline & Life boat crew \\
\hline \multirow{4}{*}{$6 / 9$} & Royal Air Force pilot \\
\hline & Royal Air Force navigator \\
\hline & Royal Air Force aircrew \\
\hline & Fire brigade \\
\hline
\end{tabular}

\section{Results}

We included in the study the 8861 people at age 16 who were eligible, of whom 53\% (4653) were male. In all, 95.2\% (8432) had normal vision and 4.8\% (429) had residual/persisting amblyopia: 3.6\% (320) mild and 1.2\% (109) moderate or severe. One hundred and one (1.2\%) had resolved amblyopia, and 4.3\% (384) overall and $47 \%$ (201) of those with amblyopia had strabismus. For brevity, we present only key illustrative findings here (in particular for outcomes repeatedly assessed at different ages); tables A-D on bmj.com give the full dataset described above.

\section{Education and occupation}

Children with amblyopia did as well as those with normal vision on educational tests (table 2 and table A). Amblyopia was not associated with highest educational qualification achieved (table 3). We found no association between amblyopia and being in paid employment at age 33 for men or women. Overall, $2321 / 3351(69 \%)$ of men had experienced some degree of upward shift in social class; we found no evidence that those with amblyopia had a different pattern (upward shift in 69\% for normal, $73 \%$ for mild, and $63 \%$ for moderate or severe amblyopia; $\mathrm{P}=0.413)$.

Overall, people with amblyopia were as likely as those with normal vision to be in any "target" occupation. ${ }^{11}$ Specifically, $7.7 \%$ (95\% confidence interval $6.7 \%$ to $8.6 \%)$ of men with normal vision and $5.7 \%$ (1.8\% to $9.6 \%)$ of those with amblyopia $(\mathrm{P}=0.397$ for difference in proportion) were in any of these occupational categories. As the total number of people with amblyopia was small ( 7 mild, 1 moderate/severe amblyopia), further formal analysis was not possible, but only the person with moderate/severe amblyopia failed to meet the visual standards for his current occupation.

\section{Behaviour and social functioning}

Children with amblyopia were generally no more likely than those without amblyopia to have significant behavioural 
Table 2 Associations between mild or moderate/severe amblyopia and educational attainment during childhood

\begin{tabular}{|c|c|c|c|c|c|}
\hline \multirow{2}{*}{ Education tests (at age 11) } & \multirow{2}{*}{ Normal vision (No) } & \multicolumn{2}{|c|}{ Amblyopia } & \multirow{2}{*}{ Adjusted difference $(95 \% \mathrm{Cl})$ in scores* } & \multirow{2}{*}{$P$ value } \\
\hline & & Degree & No & & \\
\hline \multirow{2}{*}{ Maths† } & \multirow{2}{*}{5894} & Mild & 194 & $0.02(-0.10$ to 0.15$)$ & 0.705 \\
\hline & & Moderate/severe & 79 & $-0.09(-0.29$ to 0.11$)$ & 0.366 \\
\hline \multirow{2}{*}{ Reading $†$} & \multirow{2}{*}{5938} & Mild & 197 & $0.09(-0.03$ to 0.20$)$ & 0.151 \\
\hline & & Moderate/severe & 80 & $-0.14(-0.14$ to 0.24$)$ & 0.600 \\
\hline \multirow{2}{*}{ Copy-a-design† } & \multirow{2}{*}{5622} & Mild & 186 & $0.14(-0.02$ to 0.29$)$ & 0.078 \\
\hline & & Moderate/severe & 76 & $-0.11(-0.35$ to 0.13$)$ & 0.370 \\
\hline \multirow{2}{*}{ Verbal score on general ability test } & \multirow{2}{*}{5526} & Mild & 184 & $-0.34(-1.70$ to 1.01$)$ & 0.619 \\
\hline & & Moderate/severe & 73 & $-0.86(-2.99$ to 1.27$)$ & 0.427 \\
\hline \multirow{2}{*}{ Non-verbal score on general ability test } & \multirow{2}{*}{5525} & Mild & 184 & $-0.27(-1.38$ to 0.83$)$ & 0.630 \\
\hline & & Moderate/severe & 73 & $-0.03(-1.77$ to 1.71$)$ & 0.970 \\
\hline
\end{tabular}

*Normal vision minus amblyopia, adjusted for social class, sex, age at testing, family size, ever having strabismus, treatment for amblyopia, and previous test scores where appropriate. †Standardised education scores- that is, multiples of standard deviation.

problems or maladjustment at home or school (table 4, table A). Specifically, they were no more likely to be bullied, as measured by the specific item in the Rutter scale, at 7 or 11 years (odds ratio $1.09,0.59$ to $2.00, \mathrm{P}=0.781$ for mild at age $7 ; 1.51,0.63$ to 3.61 , $\mathrm{P}=0.354$ for moderate/severe at age $7 ; 0.75,0.36$ to 1.60 , $\mathrm{P}=0.462$ for mild at age $11 ; 0.62,0.21$ to $1.89, \mathrm{P}=0.404$ for moderate/severe at age 11: adjusted for sex, social class, and ever having had a strabismus). We found no evidence for an association between amblyopia and participation in social activities in either childhood or adult life (tables 3 and 4). Children with amblyopia were as likely as those with normal vision to play sport or outdoor games (table 4, table A). Overall, $<1 \%$ had

Table 3 Associations between mild or moderate/severe amblyopia and education, employment, social activities, unintended injuries, general and mental health in adult life

\begin{tabular}{|c|c|c|c|c|c|}
\hline \multirow{2}{*}{ Outcome } & \multirow{2}{*}{$\begin{array}{l}\text { Normal vision } \\
\quad \text { (No) }\end{array}$} & \multicolumn{2}{|c|}{ Amblyopia } & \multirow{2}{*}{$\begin{array}{c}\text { Adjusted odds ratio (95\% Cl) (amblyopia } v \\
\text { normal vision) }\end{array}$} & \multirow{2}{*}{$P$ value } \\
\hline & & Degree & No $(\%)$ affected & & \\
\hline \multicolumn{6}{|l|}{ Education (at age 33 )* } \\
\hline \multirow{2}{*}{ Higher educational attainment } & \multirow{2}{*}{4965} & Mild & 184 & 1.22 (0.91 to 1.64$)$ & 0.189 \\
\hline & & Moderate/severe & 65 & 0.99 (0.61 to 1.61$)$ & 0.962 \\
\hline \multicolumn{6}{|l|}{ Employment (at age 33)† } \\
\hline \multirow{2}{*}{ In paid employment (men) } & \multirow{2}{*}{2416} & Mild & $69 / 90(77)$ & 0.93 (0.55 to 1.60$)$ & 0.805 \\
\hline & & Moderate/severe & $22 / 33(67)$ & 0.51 (0.22 to 1.17$)$ & 0.112 \\
\hline \multirow{2}{*}{ In paid employment (women) } & \multirow{2}{*}{2502} & Mild & $59 / 91 \quad(56)$ & 0.92 (0.57 to 1.50$)$ & 0.747 \\
\hline & & Moderate/severe & $16 / 27(60)$ & 0.71 (0.31 to 1.64$)$ & 0.427 \\
\hline \multicolumn{6}{|l|}{ Sport and social functioning (at age 23)‡ } \\
\hline \multirow{2}{*}{ Not done any sport in previous month } & \multirow{2}{*}{6592} & Mild & 117/237 (49) & 0.94 (0.71 to 1.26$)$ & 0.686 \\
\hline & & Moderate/severe & $41 / 82(50)$ & 1.07 (0.65 to 1.75$)$ & 0.800 \\
\hline \multirow{2}{*}{ Not been dancing in previous month } & \multirow{2}{*}{6592} & Mild & $101 / 238$ (42) & 1.00 (0.76 to 1.34$)$ & 0.954 \\
\hline & & Moderate/severe & $33 / 82(40)$ & 0.88 (0.54 to 1.44$)$ & 0.610 \\
\hline \multirow{2}{*}{ Not been to the cinema in previous month } & \multirow{2}{*}{6598} & Mild & $150 / 238(63)$ & 0.87 (0.65 to 1.16$)$ & 0.339 \\
\hline & & Moderate/severe & $49 / 82(60)$ & 0.76 (0.46 to 1.25$)$ & 0.283 \\
\hline \multicolumn{6}{|l|}{ General health (at age 33)§ } \\
\hline \multirow{2}{*}{ Self report of poorer health } & \multirow{2}{*}{3579} & Mild & 121 & $1.04(0.73$ to 1.49$)$ & 0.839 \\
\hline & & Moderate/severe & 51 & 1.12 (0.64 to 1.95$)$ & 0.700 \\
\hline \multicolumn{6}{|l|}{ Mental health (at age 33) } \\
\hline \multirow{2}{*}{$\begin{array}{l}\text { Depression, seen general practitioner or specialist in past } \\
10 \text { years }\end{array}$} & \multirow{2}{*}{3578} & Mild & $21 / 120(18)$ & 1.54 (0.93 to 2.56$)$ & 0.093 \\
\hline & & Moderate/severe & $8 / 50(16)$ & 1.61 (0.74 to 3.53$)$ & 0.233 \\
\hline \multirow{2}{*}{ Psychological distress (malaise inventory score $>7$ ) } & \multirow{2}{*}{3471} & Mild & 9/117 (8) & 0.88 (0.41 to 1.90$)$ & 0.754 \\
\hline & & Moderate/severe & $4 / 49(8)$ & 1.29 (0.44 to 3.79$)$ & 0.649 \\
\hline \multicolumn{6}{|l|}{ Unintentional injuries (at age 17-33)‡ } \\
\hline Innotiont apro & 5255 & Mild & $33 / 198(17)$ & 1.56 (1.03 to 2.38$)$ & 0.037 \\
\hline Inpatient care & 5355 & Moderate/severe & 9/72 (13) & 1.09 (0.50 to 2.40$)$ & 0.826 \\
\hline Outnationt care & 5256 & Mild & 104/198 (53) & 0.90 (0.65 to 1.24$)$ & 0.517 \\
\hline Outpatient care & 5356 & Moderate/severe & $44 / 72(61)$ & 1.04 (0.60 to 1.82 ) & 0.882 \\
\hline Boad accident as driver & 5390 & Mild & $39 / 200(20)$ & 1.28 (0.87 to 1.89$)$ & 0.210 \\
\hline Road accident as driver & 5390 & Moderate/severe & $22 / 72$ (31) & 2.33 (1.29 to 4.20$)$ & 0.005 \\
\hline Iniury at work & 5390 & Mild & $39 / 200(20)$ & 0.78 (0.52 to 1.17$)$ & 0.226 \\
\hline Injury at work & 5390 & Moderate/severe & $17 / 72$ (24) & 0.76 (0.40 to 1.45 ) & 0.408 \\
\hline
\end{tabular}

${ }^{*}$ Ordinal regression—odds of achieving higher level of education, independent of actual level considered, adjusted for sex, social class, marital status, ever having strabismus, and treatment for amblyopia.

†Adjusted for highest educational attainment, social class, ever having strabismus, and treatment for amblyopia.

†Adjusted for sex, social class, ever having strabismus, and treatment for amblyopia.

§Ordinal regression—odds of self report of poorer health, independent of level, adjusted for highest educational attainment, marital status, home behaviour at 16 years, sex, school adjustment at 16 years, previous mental health, and change in social class in previous 10 years.

IAdjusted for highest educational attainment, marital status, home behaviour at 16 years, sex, school adjustment at 16 years, previous mental health, and change in social class in previous 10 years. 


\begin{tabular}{|c|c|c|c|c|c|}
\hline \multirow{2}{*}{ Outcome } & \multirow{2}{*}{$\begin{array}{l}\text { Normal vision } \\
\text { (No) }\end{array}$} & \multicolumn{2}{|c|}{ Amblyopia } & \multirow{2}{*}{ Adjusted odds ratio $(95 \% \mathrm{CI})^{*}$} & \multirow{2}{*}{$P$ value } \\
\hline & & Degree & No (\%) affected & & \\
\hline \multirow{2}{*}{ Behaviour (at age 7): BSAG score, in upper decile } & \multirow{2}{*}{6987} & Mild & $24 / 234(10)$ & $1.20(0.77$ to 1.88$)$ & 0.419 \\
\hline & & Moderate/severe & $14 / 94(15)$ & $1.73(0.92$ to 3.23$)$ & 0.087 \\
\hline \multirow{2}{*}{ Sport (at 11 years): "hardly ever" } & \multirow[b]{2}{*}{6463} & Mild & $24 / 210(11)$ & $1.15(0.72$ to 1.85$)$ & 0.550 \\
\hline & & Moderate/severe & $9 / 89(10)$ & 1.02 (0.47 to 2.22$)$ & 0.951 \\
\hline \multirow{2}{*}{ Social activities—dancing/disco (at 16 years): "hardly ever" } & \multirow{2}{*}{5778} & Mild & $74 / 216(34)$ & 1.32 (0.96 to 1.82$)$ & 0.086 \\
\hline & & Moderate/severe & $20 / 75(27)$ & 0.86 (0.49 to 1.53$)$ & 0.611 \\
\hline \multicolumn{6}{|l|}{ Unintentional injuries needing hospital care: } \\
\hline \multirow{2}{*}{ Inpatient care up to age 16} & \multirow{2}{*}{6757} & Mild & $71 / 255(28)$ & 1.17 (0.86 to 1.59$)$ & 0.319 \\
\hline & & Moderate/severe & $19 / 88 \quad(22)$ & 0.76 (0.44 to 1.33$)$ & 0.334 \\
\hline \multirow{2}{*}{ Outpatient care at age $12-16$} & \multirow{2}{*}{6807} & Mild & $60 / 257(23)$ & 0.89 (0.65 to 1.23$)$ & 0.482 \\
\hline & & Moderate/severe & $25 / 89(28)$ & $1.05(0.62$ to 1.76$)$ & 0.858 \\
\hline
\end{tabular}

BSAG=Bristol social adjustment guides.

*Amblyopia $v$ normal vision, adjusted for social class, sex, ever having strabismus, and treatment for amblyopia.

poor coordination $(0.3 \%, 0.2 \%$ to $0.4 \%$ with normal vision and $0.4 \%, 0 \%$ to $1.1 \%$ with amblyopia, $\mathrm{P}=0.403$ ), so further formal analysis was not possible.

\section{Health}

People with amblyopia were no more likely than those with normal vision to report poor general health (table 3, table B). Equally, they were no more likely to report depression or psychological distress in adult life. Overall, 213 (2.4\%) people died between 16 and 41 years, including $5(1.2 \%)$ of those who had amblyopia. The small numbers precluded further formal analysis. Overall, people with amblyopia were no more likely than those with normal vision to have unintended injuries in childhood requiring inpatient or outpatient hospital care (table 4 , table A). In adult life, amblyopia was not associated with increased odds of injuries at work. Moderate/severe (but not mild) amblyopia was associated with road traffic accidents as a driver between ages 17 and 33. An isolated association between mild amblyopia and injuries needing inpatient care occurred, but no such associations existed with either moderate/severe amblyopia or outpatient care (table 3, table B). The interpretation of this observation, as of other isolated statistically significant associations, is difficult in the context of multiple comparisons.

\section{Discussion}

Our findings indicate that, on average, people with amblyopia can expect to do as well as their peers with normal vision in both eyes in terms of educational attainment, employment, and occupational and socioeconomic achievement. They do not seem to be disadvantaged in relation to social activities, nor are they at increased risk of behavioural difficulties or social maladjustment as children. They are no more likely to report overall worse general health or mental health, to be involved in serious unintended injuries generally, or to be at overall increased risk of death.

\section{Strengths and weaknesses of the study}

Reliance on parental history for some information and on assessments by general medical examiners (rather than ophthalmologists) raises the possibility of misclassification of amblyopia. However, visually impairing disease is rare in childhood, ${ }^{12}$ and amblyopia is the most likely cause of unilateral reduced acuity despite optical correction. Thus, most people with amblyopia were probably correctly classified, and they also probably account for most "cases." This is supported by our prevalence of $1.2 \%$ for residual amblyopia at a threshold of $6 / 18$ or worse, which is consistent with previous reports. ${ }^{13}{ }^{14}$ The 1958 birth cohort is a representative population, studied longitudinally, ensuring that visual status was known before measurement of a range of important outcomes. This confers important advantages for studying the functional consequences of amblyopia; the size of the population studied was sufficient to detect even modest associations, for key outcomes, where they exist. No directly comparable previous work in this area exists, but indirect comparisons are made below.

\section{Implications of findings}

Extensive psychophysical and neurophysiological work has elegantly delineated clear deficits in specific components of vision, such as contrast sensitivity, that occur in amblyopia. ${ }^{2}$ Our findings fail to identify their "real life" functional correlates. For example, the reading speed of people with amblyopia may be measurably slower but may nevertheless, on average, be adequate for educational or occupational purposes. Experimental work will remain the foundation for advancing understanding of visual development and the pathophysiology of amblyopia, but its value to decisions about screening needs to be enhanced by considering the impact of specific visual abnormalities on everyday activities, as well as the degree to which these are permanently reversed by treatment.

Screening for amblyopia became established in an era when the benefits and harms of interventions were often less rigorously scrutinised than now; the two major justifications were statutory occupational preclusion and the risk of visual impairment if the affected person lost vision in their normal eye. We recently showed that in the UK the lifetime risk to people with amblyopia of visual impairment or blindness through disease or injury to their normal eye is between $1 \%$ and $3 \%{ }^{15}$ This risk, and the attendant consequences such as permanent loss of paid employment, are more common than previously thought and now seem to be consistent across populations. ${ }^{16}$ Although important, this event is, nevertheless, likely to be too rare at a whole population level (affecting 4.8-14.4/10 000 of the whole population ${ }^{15}$ ) to alone be sufficient justification for screening for all levels of amblyopia, especially in the current climate of competition for finite health care resources. A stronger case can be made for screening for moderate and severe amblyopiausing, for example, the minimum visual standards for driving as the threshold for acuity in the amblyopic eye-to identify people who would have predictable and measurable adverse outcomes should they lose the use of their non-amblyopic eye. This argument is supported by recent UK data from a randomised 
trial of the outcomes of preschool vision screening for and treatment of unilateral visual loss. ${ }^{17}$

The limited literature to date on the general employment and specific occupational limitations associated with amblyopia, and their implications for socioeconomic advancement, suggests that it has little impact on occupational class. ${ }^{16}$ Our findings strengthen this view. The proportion of the population working in the "target" occupations to which acuity restrictions apply in the UK is not high $(7.6 \%)$, so less than $4 / 1000$ people overall (that is, those with amblyopia) would face potential occupational preclusion. Notably, we found no evidence for differential impact of occupational preclusion by social class, and injuries in the workplace were no more common among people with amblyopia. Importantly, to justify screening for amblyopia as a means of obviating potential occupational preclusion, certainty would be needed that good improvements in acuity (and for some occupations normal vision) can be achieved with treatment in childhood and that these are sustained throughout adult life in all cases. Current data suggest that such improvement is neither universal nor accurately predictable ${ }^{18-20}$ Opportunities for future population based work on long term outcomes may arise in the context of existing birth cohort studies, ${ }^{21}$ as well as other longitudinal studies and clinical treatment trials. Finally, we urge ophthalmic professionals to engage in work delineating the safety risks associated with amblyopia, so that affected people are advised more informatively and occupational preclusions are more firmly evidence based.

We recognise that our study does not examine the qualitative impact of amblyopia at the level of the individual. Previous work in this area has mainly examined the impact of treatment (occlusion or glasses) or associated manifest strabismus, rather than of amblyopia itself. ${ }^{22-24}$ Information about the impact on quality of life of unilateral visual loss acquired through disease or injury in adult life cannot be extrapolated to amblyopia. Methodologically robust research, ideally combining qualitative and quantitative approaches and based on representative population samples, would be of value in characterising the nature and degree of limitation to everyday life of people with amblyopia, and whether, and how, this is related to severity of amblyopia. This could be complemented by information obtained through routine assessment of vision related quality of life in a clinical setting, as well as in specific research studies, including treatment trials, on amblyopia. Elaboration of the nature and severity of the disability conferred by amblyopia, and the extent to which it is improved by treatment, is essential to further characterising its public health importance, which remains uncertain.

\section{Conclusions}

We suggest that the need is greater than ever before for concerted research on what it means to be amblyopic and, importantly, how this varies with severity of amblyopia and how it changes with treatment, so that screening programmes can be designed to best serve those people who have the most to gain from the earliest possible identification.

For archived data we thank the Centre for Longitudinal Studies (Institute of Education), National Birthday Trust Fund, National Children's Bureau, City University Social Statistics Research Unit, and the Data Archive distributor, SN:3138, Colchester. Research at the Institute of Child Health and Great Ormond Street Hospital for Children NHS Trust benefits from R\&D funding received from the NHS Executive. We thank David Taylor for commenting on an earlier version of this manuscript. JSR holds a joint appointment with the Institute of Ophthalmology, London.

Contributors: All authors contributed to the design, analysis, and interpretation of data and writing of this article and have given final approval of the version to be published. JSR is the guarantor.
Funding: The work reported here was supported by a project grant from the BUPA Foundation, which had no role in the design or conduct of the study or in the decision to publish.

Competing interests: None declared.

Ethical approval: This study is part of a broader programme of work approved by the Institute of Child Health's Research Ethics Committee.

1 Wiesel TN. Postnatal development of the visual cortex and the influence of environment. Nature 1982;299:583-91.

2 Levi DM, Carkeet A. Amblyopia: a consequence of abnormal visual development. In: Simons K, ed. Early visual development - normal and abnormal. New York: Oxford University Press, 1993:391-408.

3 Snowdon S, Stewart-Brown S. Preschool vision screening: results of a systematic review. University of York, NHS Centre for Reviews and Dissemination, 1997. (CRD Report 9.) Hall DM, Elliman D, eds. Health for all children. 4th ed. Oxford: Oxford University Press, 2003.

Rahi JS, Dezateux C. The future of preschool vision screening services in Britain. BMJ 1997:315:1247-8.

6 National Child Development Study, 2004. www.cls.ioe.ac.uk

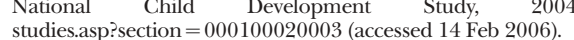

studies.asp?section $=000100020003$ (accessed 14 Feb 2006).
Jefferis BJMH, Power C, Hertzman C. Birth weight, childhood socioeconomic environment, and cognitive development in the 1958 British birth cohort study. BMJ 2002;325:305-8

8 Stott DH. The social adjustment of children: manual to the Bristol social adjustment guides. London: Hodder and Stoughton, 1987.

9 Rutter M, Tizard J, Whitmore K. Education, health and behaviour. London: Longman, 1970.

10 Department of Employment. Classification of occupations and directory of occupational titles (CODOT). London: HMSO, 1972.

11 Adams GGW, Karas MP. Effect of amblyopia on employment prospects. Br J Ophthalmol 1999;83:380.

12 Rahi JS, Cable N, on behalf of the British Childhood Visual Impairment Study Group (BCVISG). Severe visual impairment and blindness in children in the UK. Lancet 2003;362:1359-65

13 Attebo K, Mitchell P, Cumming R, Smith W, Jolly N, Sparkes R. Prevalence and causes of amblyopia in an adult population. Ophthalmology 1998;105:154-9.

14 Williams C, Northstone K, Harrad R, Sparrow JM, Harvey I, ALSPAC Study Team. Amblyopia treatment outcomes after screening before or at age 3 years: follow up from randomised trial. $B M J$ 2002;324:1549-51.

15 Rahi JS, Logan S, Timms C, Russell-Eggitt I, Taylor DSI. Risk, causes, and outcomes of visual impairment after loss of vision in the non-amblyopic eye: a population-based study. Lancet 2002;360:597-602.

16 Chua B, Mitchell P. Consequences of amblyopia on education, occupation, and long-term vision loss. Br J Ophthalmol 2004;88:1119-21.

17 Clarke MP, Wright CM, Hrisos S, Anderson JD, Henderson J, Richardson SR. Randomised controlled trial of unilateral visual impairment detected at preschool vision screening. BMJ 2003;327:1251-4.

18 Bowman RJC, Williamson TH, Andrews R, Aitchison TC, Dutton GN. An inner city preschool visual screening programme: long-term results. $\mathrm{Br} J$ Ophthalmol 1998;82:543-8.

19 Leiba H, Shimshoni M, Oliver M, Gottesman N, Levartovsky S. Long-term follow-up of occlusion therapy in amblyopia. Ophthalmology 2001;108:1552-5.

20 Holmes JM, Beck RW, Kraker RT, Astle WF, Birch EE, Cole SR, et al. Risk of amblyopia recurrence after cessation of treatment. J AAPOS 2004:8:420-8.

21 Millennium Cohort, 2004. www.cls.ioe.ac.uk/studies.asp?section $=000100020001$ (access $14 \mathrm{Feb}$ 2006).

22 Packwood EA, Crusz OA, Rychwalski MD, Keech RV. The psychosocial effects of amblyopia study. J AAPOS 1999;3:15-7.

23 Horwood J, Waylen A, Herrick D, Williams C, Wolke D. Common visual defects and peer victimization in children. Invest Ophthalmol Vis Sci 2005;46:1177-81.

24 Hrisos S, Clarke MP, Wright CM. The emotional impact of amblyopia treatment in preschool children: randomized controlled trial. Ophthalmology 2004;111:1550-6. (Accepted 30 January 2006)

doi 10.1136/bmj.38751.597963.AE

\section{What is already known on this topic}

Amblyopia is the most common disorder seen in paediatric ophthalmic practice in industrialised countries

Debate about the value of established whole population screening partly reflects the paucity of evidence of the functional consequences of amblyopia and their impact at a population level

\section{What this study adds}

Distinguishing, at a population level, between the lives of people with amblyopia and those without in terms of important educational, health, and social outcomes may be difficult 
Research

Centre for Paediatric Epidemiology and Biostatistics, Institute of Child Health,

London WC1N 1EH

C S Peckham professor of paediatric epidemiology

J S Rahi senior clinical lecturer

Correspondence to:J S Rahi j.rahi@ich.ucl.ac.uk

P M Cumberland senior research fellow 